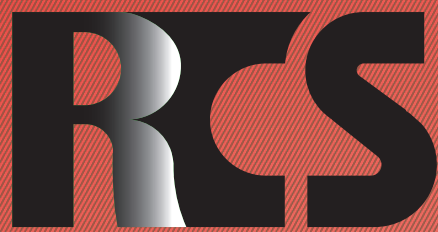

Depósito legal ppi $201502 Z U 4662$

Esta publicación científica en formato digital es continuidad de la revista impresa Depósito Legal: pp $197402 Z$ U789

- ISSN: 1315-9518 • ISSN-E: 2477-9431

Revista de Ciencias Sociales

Universidad del Zulia. Revista de la Facultad de Ciencias Económicas y Sociales Vol. XXVII,

No. 4,2021

Revista d

Sociales

Esta publicación científica en formato digital es continuidad de la revista impresa Depósito Legal: pp $197402 Z 1789$ ISSN: 1315-9518 


\title{
Videojuegos y subjetividades: Una reflexión desde Hispanoamérica
}

\author{
Acevedo-Merlano, Álvaro* \\ Ortiz Záccaro, Zulma**
}

\begin{abstract}
Resumen
Los videojuegos como productos culturales, encierran toda una potencialidad en clave de significados y otorgan posibilidades de manifestar posiciones enunciativas divergentes por parte de colectividades no hegemónicas. El objetivo de este ensayo es analizar la relación que existe entre el consumo cultural de videojuegos y la construcción de subjetividades en los jugadores hispanoamericanos. Se trata de una investigación documental a partir de la búsqueda de publicaciones científicas, a fin de seleccionar los artículos con mayores índices de impacto, que abordaron la temática en cuestión. Se observó que prevalecen los géneros de videojuegos de acción y aventura, de disparos en primera y tercera persona con narrativas mítico-heroicas para que los usuarios trasciendan en una situación épica en el marco resistencia - poder entre jugadores norteamericanos angloparlantes y latinoamericanos hispanohablantes generando dinámicas de exclusión migratoria en el espacio virtual. Se concluye, que las subjetividades de los video-jugadores se construyen mediante las interrelaciones que se producen entre los sujetos y la dinámica en la que se desarrolla el juego, incorporando a su constructo tanto valores como sentimientos y significados.
\end{abstract}

Palabras clave: Videojuegos; subjetividades; consumo cultural; Hispanoamérica; género.

* Doctorando en Bioética. Magister en Educación (Línea Cibercultura). Magister en Ciencias de la Comunicación con énfasis en TIC. Antropólogo. Profesor en la Universidad de la Costa (CUC), Colombia. E-mail: alvaroacevedomerlano@gmail.com (iD ORCID: https://orcid.org/0000-0002-0131$\underline{0276}$

** Magister en Ciencias de la Comunicación con énfasis en TIC. Comunicadora Social con énfasis en Desarrollo Comunitario. Profesora de la Universidad de la Costa, Colombia, en el Programa de Comunicación Social y Medios Digitales. Coordinadora del área académica Desarrollo Social y el Semillero de Investigación de Comunicación Aplicada (Barranquilla, Colombia). E-mail: zortiz1@, cuc.edu.co; zulmazoraida@gmail.com (iD) ORCID: https://orcid.org/0000-0003-4973-688X

Recibido: 2021-06-09 - Aceptado: 2021-08-25 


\title{
Videogames and subjectivities: A reflection from Hispano-American
}

\begin{abstract}
Videogames as cultural products, contain a whole potentiality in terms of meanings and grant possibilities of expressing divergent enunciative positions on the part of non-hegemonic collectivities. The objective of this essay is to analyze the relationship that exists between the cultural consumption of video games and the construction of subjectivities in Hispanic American players. It is a documentary research based on the search for scientific publications, in order to select the articles with the highest impact indexes, which addressed the subject in question. It was observed that the genres of action and adventure video games prevail, of first- and third-person shooter with mythical-heroic narratives so that users transcend an epic situation in the resistance - power framework between English-speaking North American players and Spanish-speaking Latin American players, generating dynamics of migratory exclusion in virtual space. It is concluded that the subjectivities of video players are constructed through the interrelationships that occur between the subjects and the dynamics in which the game develops, incorporating values, feelings and meanings into its construct.
\end{abstract}

Keywords: Video game; subjectivities; cultural consumption; Hispanic America; gender.

\section{Introducción}

El fenómeno de los videojuegos ha tenido una gran propagación en las últimas décadas, a causa de la inclusión de las Tecnologías de la Información y la Comunicación (TIC) en la vida cotidiana de occidente. Su difusión y consumo ha sido tan amplio que actualmente es una de las industrias culturales más poderosas del planeta, compitiendo par a par con la industria del cine. Al respecto, Venegas (2019) plantea que:

Las subjetividades históricas más populares y emergentes dentro de la cultura digital contemporánea acuden al cine de masas para conseguir legitimarse a través de la activación de la «cámara de resonancia» del consumidor sin llegar a cuestionarla ni separarse de ella. Esta decisión convierte a los videojuegos históricos en un producto mercantilizado cuya principal finalidad es la evasión y el entretenimiento realizado por y para el presente más inmediato. Se vacían de significado y se emplean como escenario donde se suceden imágenes espectaculares. (p.129)

Pero ¿Qué es un videojuego? se puede argumentar que los videojuegos son la articulación entre lo que se entiende tradicionalmente como juego y las TIC. Así, los videojuegos se han convertido en uno de los pasatiempos más practicados por la juventud contemporánea, sin la excepción de otros grupos etarios. Incluso en el proceso enseñanza-aprendizaje, "aportan una nueva visión del acto académico, puesto que el alumno ve y comprueba que aquellos elementos digitales presentes en su vida cotidiana tienen un valor más allá que el puro entretenimiento" (Marín, Morales y Reche, 2020, p.96).

En ese sentido, en los videojuegos, especialmente los online, donde existe una gran cantidad de personas interactuando, a veces a nivel masivo y simultáneamente, se generan un gran cúmulo de relaciones que, dependiendo del juego, pueden entrenar al jugador en habilidades como la tolerancia a la frustración, las relaciones interpersonales, nuevas formas de trabajo en equipo, el desarrollo del liderazgo y la negociación o, por otra parte, pueden incentivar la construcción de conocimiento de manera colectiva y conectiva (Acevedo-Merlano, 2018; Arbeláez-Campillo, Villasmil y Rojas-Bahamón, 2021). 
Algunos juegos también pueden enseñar a los jugadores respecto a las maneras de relacionarse con los demás, puesto que se pueden generar penalizaciones desde la colectividad en rechazo a un comportamiento considerado como negativo, deshonesto o anti cooperativo. A tenor de lo expuesto, se puede observar que mediante estas coerciones sociales los jugadores moldean su comportamiento, aprendiendo por vía propia cómo sus acciones traen consecuencias negativas o positivas, contribuyendo de esa manera a forjar algunas habilidades y destrezas sociales.

Resulta importante acercarse a las potencialidades que estos dispositivos de juego poseen en la construcción de las subjetividades de los jugadores, mientras que a través de la interactividad de los entornos virtuales continúan expandiéndose las relaciones, alianzas y redes creadas por todos ellos a lo largo y ancho del globo. Ese grupo de jugadores traspasando la línea del simple consumo pasivo, terminan convirtiéndose en lo que Islas-Carmona (2008) llama prosumidores, en tanto intervienen al videojuego modificándolo en su estructura, sobrepasando las posibilidades dadas por el diseño predeterminado del software que hace posible el juego.

En el contexto Hispanoamericano estas tecnologías de juego están mucho más presentes de lo que comúnmente se piensa; en innumerables municipios, poblados y hasta corregimientos se pueden encontrar varios salones de videojuegos muy parecidos a las salas de Arcades populares en los años 80, caracterizadas por Belli y López (2008), en las que con pocas monedas era posible acceder a una de estas robustas máquinas.

Estos salones de videojuegos actuales se encuentran equipados, no por Arcades perfiladas para un uso masivo, sino por consolas caseras como Xbox, Nintendo, PlayStation y Sega, entre otros, diseñadas únicamente para una manipulación doméstica. Se trata de establecimientos, que muchas veces son las salas de cualquier vivienda, acondicionadas para tal fin, estos espacios están presentes en muchas poblaciones rurales y barrios periféricos de las grandes urbes, en los que el costo por una hora de juego puede oscilar alrededor de 1 USD, a diferencia de los salones recreativos, en los que el jugador podía permanecer jugando hasta finalizar el juego, o en su defecto, hasta perder su turno (Acevedo y Chaux, 2016).

Estas instalaciones domésticas, conocidas simplemente como salas de videojuegos, funcionan gracias a la apropiación que tuvieron los sectores populares sobre estas tecnologías, al adaptar estos aparatos que fueron diseñados desde su concepción como dispositivos para el espacio doméstico, convirtiéndolos hoy en día en los principales responsables de la difusión popular de los videojuegos en el ámbito de lo público a lo largo de las urbes y poblados hispanoamericanos.

En efecto, a causa de la amplia difusión de la economía informal y de situaciones como la piratería, han facilitado la posibilidad de contrabandear estos dispositivos, por tanto, han logrado llegar a poblaciones periféricas a unos costos asequibles. Esto ha permitido el acceso a estas tecnologías de juego, y en última instancia a un amplio consumo.

A tenor de lo anterior, el objetivo de este ensayo es analizar la relación que existe entre el consumo cultural de videojuegos y la construcción de subjetividades en los jugadores hispanoamericanos; se presentan reflexiones producto de la investigación documental cuyo recorrido se realiza a partir de la búsqueda de publicaciones científicas, a fin de seleccionar los artículos con mayores índices de impacto, que abordaron la temática en cuestión para la respectiva interpretación y análisis de las categorías estudiadas.

La reflexión expuesta gira en torno a las perspectivas de estudio sobre videojuegos en Hispanoamérica, se presenta a través de dos secciones: En primer lugar, la mirada sociocultural y la crítica decolonial; y en segunda instancia, desde el enfoque de género. Finalmente, se presentan las conclusiones a la luz de los hallazgos más significativos de la investigación realizada que si bien aclaran algunos interrogantes, permiten incorporar 
nuevas inquietudes que motivarán nuevos estudios al respecto.

\section{Estudio sobre videojuegos en Hispanoamérica desde la perspectiva sociocultural y la crítica decolonial}

Trabajos como los de Cabra (2010), argumentan que el videojuego es un dispositivo comunicativo en el que circulan las meta-narrativas seculares modernas, en donde se encuentran las respuestas sobre preguntas arcaicas relacionadas a la existencia que le otorgan una explicación al mundo contemporáneo, a las posibilidades que pueden ocurrir en el futuro, y a las que fueron acontecimientos que marcaron lo que se concibe actualmente como el presente.

Los videojuegos, son dispositivos que configuran elecciones narrativas muy particulares, en dónde las tecnologías han implantado la fuerza de la interactividad y la construcción de una realidad virtual que ha llevado a alteraciones temporales, y a que las narrativas de la ciencia ficción, por ejemplo, se entiendan como la realización de utopías de un futuro con el que se puede interactuar por medio del juego.

Esto logra que estas tecnologías lúdicas, pasen de ser narrativas a ser participativas, sobre una temporalidad hipertextual que enfatiza en la ruptura narrativa, superando la lógica lineal determinada por la poética de Aristóteles, para dar paso a la discontinuidad y la interactividad del hipertexto. Los videojuegos forman el inicio de las narrativas hipermediales e hipertextuales, que se fundamentan en la ruptura de cualquier imposición secuencial (Cabra, 2010).

En ese sentido, teniendo en cuenta a Corona (2016), se puede afirmar que el proceso en el que se genera la identificación con el avatar de un videojuego no ocurre de facto, ni tampoco se convierte en algo deseable o enriquecedor en sí mismo, puesto que se concibe como algo problemático desarrollado en un ejercicio de relaciones en el que se concibe la diferencia con "El Otro", diferente al occidental.

Lo antes descrito, genera relaciones de poder asimétricas, pues muchos videojuegos reproducen relaciones desiguales de poder y de violencia simbólica en donde hay un universo en el que las minorías étnicas y de género no son representadas lo suficiente; son escasamente visibilizadas como subjetividades o colectividades protagonistas dentro de las tramas y las narrativas que ahí se dan, pues, en la mayoría de los casos los avatares son diseñados concibiendo al hombre blanco occidental como el principal protagonista, mostrando de esa manera a la otredad como un elemento que posee muchas características de deshumanización.

Este tipo de producciones culturales se encuentran focalizadas en centros de poder, en los que se construyen las concepciones e ideas de superioridad del hombre blanco, occidental, heterosexual, frente al otro pasivo salvaje o amenazante; legitimando con eso la capacidad de agencia del hombre blanco occidental frente o en contraste con la presunta impotencia e incapacidad del "otro" (Corona, 2016).

El consumo directo de videojuegos ocurre con más intensidad en los países desarrollados; sin embargo, con los videojuegos online se pueden generar relaciones entre estos diferentes contextos, pues las colectividades conformadas por grupos de personas y jóvenes que comparten el mismo culto por la tecnología lúdica, se concentran en el consumo de estos videojuegos sin importar el lugar geográfico. Así, según Loayza (2010), el videojuego online es la máxima expresión de los productos simbólicos dinamizados en la socialización y el entretenimiento de redes colaborativas masivas de consumos culturales.

No obstante, el efecto on-line aumenta los participantes simultáneos, modificando las interacciones entre jugadores norteamericanos angloparlantes e hispanoamericanos, generando dinámicas de exclusión de migración, en donde el norteamericano reconoce el espacio online en que se encuentra jugando el videojuego como un espacio nacional norteamericano, persiguiendo al 
hispano hablante como alguien inmigrante en ese espacio, que a diferencia de lo que percibe, es un espacio transnacional que no responde a esas fronteras.

Ahora bien, como el juego es desarrollado en Norteamérica, se piensa que el espacio virtual les pertenece por considerarlo su territorio nacional; es así como los jugadores angloparlantes acosan a los demás que no manejan su idioma y los catalogan como agentes externos (Loayza, 2010).

Por su parte Torres-Parra (2013), considera que el videojuego es una interfaz donde se negocian los significados que generalmente circulan en los medios masivos hegemónicos, planteando expresiones de resistencia al poder simbólico dominante. En ese sentido, la producción de videojuegos en lugares periféricos a la hegemonía del poder que producen las industrias culturales se puede entender como una respuesta de-colonial, basada en unas narraciones que discrepan de las oficiales.

Producir videojuegos desde la periferia puede evidenciar otra cara de la historia que reproducen las narrativas oficiales y más difundidas; por tanto, se pueden concebir como dispositivos de resistencia de-coloniales; acercándolos a "tecnologías opositivas", entendidas como estrategias que consolidan espacios de expresión desde lugares donde los oprimidos generan maneras de resistencia desde la tecnología, como procesos para descolonizar la imaginación, creando nuevos relatos en el campo de lo mediático, pues las transformaciones que han posibilitado las tecnologías pueden implementarse como una oportunidad de hacer visible al oprimido y reivindicar sus derechos (Torres-Parra, 2013).

\section{Estudio sobre videojuegos en Hispanoamérica desde el enfoque de género}

Desde esta perspectiva, Navone (2016), plantea que los videojuegos son medios reproductores de valores, representaciones y símbolos, que actúan como productos culturales en la construcción del género y su representación, a través de narrativas femeninas y masculinas, permeadas por el estereotipo del Héroe Salvador o la damisela en apuros.

Del mismo modo, expresa que los videojuegos utilizan la narrativa míticoheroica siempre como un recurso en el que los usuarios encuentran la promesa de trascender en un personaje que transita un camino dentro de una situación épica, en una sexualidad que se encuentra implícita, y donde el modelo masculino es el que se impone.

Navone (2016), señala que aparecen unas relaciones de poder asimétricas que se reproducen a través de una masculinidad épica arbitraria que reproduce un sistema de dominación patriarcal, en el que la masculinidad heroica, como una forma hegemónica de la identidad, coloca al hombre por encima de cualquier otra manifestación o modelo de hacer femenino, donde la "masculinidad hegemónica" motiva e impulsa a los hombres convencidos que son capaces de dominar a los otros a través de su superioridad.

Asimismo, destaca que al principio los video juegos reproducían tajantemente esta superioridad del hombre, en donde la aventura era netamente masculina (Navone, 2016); sin embargo, actualmente existen muchas aventuras sustentadas por fuera de una representación masculina, lo que invita a pensar al videojuego como una tecnología que produce y reproduce, más que una representación de la masculinidad, diversos discursos potenciales de representación del género, es decir, se podría entender al videojuego como una tecnología de género.

Aunque en Hispanoamérica la brecha digital es relativamente pequeña con relación al uso de celulares en diferentes estratos socioeconómicos, para el caso de los videojuegos de consolas, según Bringué, Sádaba y Artopoulos (2014), sí se evidencian grandes diferencias, pues la experiencia con juegos de realidad aumentada como en el caso de la consola Nintendo Wii, son experiencias sólo experimentadas por la clase media alta, 
debido a los altos costos de estas consolas caseras, que difícilmente pueden ser adquiridas por consumidores de niveles socioeconómicos bajos.

Con respecto a la relación juego género de los jugadores, puede existir un sesgo de género que acapara el uso de videojuegos, basándose en que prevalece un público en su mayoría masculino; jóvenes jugadores que, en comparación con las chicas, permanecen mucho más tiempo en frente de las pantallas conectadas a consolas.

En resumen, Bringué et al. (2014) concluyen que existe una fuerte tendencia en la disminución respecto al uso de videojuegos los fines de semana, no aplicable a los "Heavy Users" quienes incrementan su consumo los fines de semana. A través de su investigación, plantean además que, con el aumento de la edad, el juego en solitario también va disminuyendo, pues los niños tienden a jugar más solitarios, pero entre más adultos son, más se incrementa su práctica del juego social.

Por su parte Cabra (2013), afirma que los videojuegos han logrado una transformación en la relación que existe entre el género y estos dispositivos, puesto que a partir del uso que se da de estas tecnologías, las dicotomías entre lo privado y lo público, lo femenino y lo masculino, comienzan a transformarse debido a que los jóvenes, al querer utilizar las consolas caseras como la Xbox y PlayStation, han venido desplazándose hacia el espacio doméstico, que anteriormente, sólo estaba destinado para las mujeres.

En esa medida, dicha modificación, en términos de usos espaciales, comienza a trastocar algunos presupuestos que van conectados con el género y con una nueva cultura de la habitación, localizada en lo privado del espacio doméstico, y configurada de manera distinta a través de una mediación tecnológica siempre en tensión con la construcción del género.

Siguiendo con los planteamientos de Cabra (2013), se evidencia que aún hoy existe un dominio de los hombres sobre la producción de contenidos en videojuegos, en los que se reflejan las narrativas de lo masculino; sin embargo, es necesario romper con las dicotomías entre lo femenino y lo masculino como antípodas, pues dichas oposiciones condenan a los sujetos a no pensar en la posibilidad de estar en el lado opuesto, por concebirse a sí mismos como una forma natural predeterminada del mundo.

De la misma forma, se plantea la existencia de unos trayectos, en donde los sujetos pueden ir de lo masculino a lo femenino, en la construcción de una identidad más flexible en términos de la diversidad al comprender el género. Es en este punto donde los videojuegos cobran relevancia, debido a que ofrecen la posibilidad de de-construir algunos de los elementos que configuran el espacio y el tiempo al que están amarradas las tradicionales concepciones del género y la corporalidad (Cabra, 2013).

Así, los videojuegos deben tratarse como un fenómeno inmerso en la cotidianidad, generadores de una nueva gama de situaciones en las que, como seres humanos, la mayoría se están reconfigurando, acudiendo a De Certeau (2000), en esas maneras de hacer en lo cotidiano, a través de un consumo activo de estos dispositivos de juegos que forman parte de la dieta mediática diaria de millones de personas alrededor del mundo y que son producidos por unas industrias culturales que codifican en los videojuegos unos mensajes intencionales que pueden, de algún modo, marcar la construcción de las subjetividades.

Asimismo, los individuos naturalizan el acercamiento e incorporación de las TIC a sus vidas cotidianas y a su intimidad, teniendo en cuenta que estos artefactos son considerados como extensiones del cuerpo humano (McLuhan, 2009) que generan posibilidades de innovación en la práctica social (Cobo, 2006).

\section{Conclusiones}

Las investigaciones de corte sociocultural o comunicacional, que contemplan al videojuego de manera imparcial, como un fenómeno que debe ser estudiado sin 
ser satanizado, son cada vez mayores, además de necesarias, pues los videojuegos deben ser comprendidos más allá de sus consecuencias positivas o negativas.

En ese sentido, los videojuegos conviene tratarlos como un fenómeno inmerso en la vida diaria, puesto que son generadores de una nueva gama de situaciones en las que, los seres humanos, se están reconfigurando, sobre todo en las maneras de hacer en la cotidianidad, a través de un consumo activo de estos dispositivos de juegos que forman parte de la vida diaria de millones de personas alrededor del mundo y que generalmente son fabricados por industrias culturales que codifican en ellos unos mensajes intencionales que pueden, de algún modo, marcar la construcción de las subjetividades.

Por otra parte, se concibe a los videojuegos como productos culturales que encierran toda una potencialidad en clave de significados, entendiéndolos como herramientas mediáticas representativas que otorgan posibilidades de manifestar posiciones enunciativas divergentes por parte de colectividades productoras no hegemónicas, y de aquellos jugadores que sobrepasan la línea del simple consumo pasivo.

Ese grupo de jugadores terminan convirtiéndose en prosumidores, en tanto logran modificar en su estructura al videojuego, sobrepasando las posibilidades dadas por el diseño predeterminado del software que hace posible el juego. Estos jugadores prosumidores de videojuegos en su práctica de interacción con sus compañeros de juego, a través de Internet intercambian ideas e información, logrando de manera colectiva realizar modificaciones considerables en sus videojuegos preferidos, creando versiones alternativas que inciden, no solo en las narrativas, sino también en el diseño y las mecánicas originales con las que fue programado el juego. En fin, la práctica del consumo de videojuegos puede alterar la forma en la que las relaciones sociales ocurren, dando paso a la creación de nuevos espacios de relacionamiento entre los sujetos jugadores (Moncada y Chacón, 2012).

Desde una perspectiva sociológica, se puede comprender la interacción entre lo social y lo tecnológico como una extensión de las capacidades humanas. Esta forma de relacionamiento con la tecnología se encuentra articulada a la manera en la que los individuos establecen el acercamiento e incorporación de las TIC a sus vidas cotidianas.

En última instancia, son los dispositivos, las consolas, los artefactos culturales, los actantes (Latour, 2008), quienes posibilitan, mediante su manejo, la apropiación de tácticas tecno-ideológicas, manifestadas en representaciones audiovisuales, multimediales e hipermediales, las cuales inciden contundentemente en la construcción de las subjetividades de quienes interactúan constantemente a través de estos dispositivos de juego.

Sí, es cierto, el consumo de videojuegos puede contribuir a la construcción de las subjetividades en los usuarios y/o consumidores, una afirmación que puede sonar determinante en cuanto la incidencia de estas tecnologías de juego en el comportamiento de quienes las consumen, y más hoy en día, donde las polémicas respecto a los contenidos de videojuegos sangrientos, violentos contra la mujer y explícitos como el caso del videojuego Rape Day (Trivi, 2019), son el pan de cada día. Pero ¿qué tipo de subjetividad se desarrolla? depende de innumerables factores que superan la misma incidencia de la herramienta tecnológica, que responde a un tema de formación previa, constante, vigilante, adyacente y posteriormente, complementaria que necesita de muchos actores, principalmente los que constituyen los núcleos sociales más cercanos, y por supuesto, la familia.

\section{Referencias bibliográficas}

Acevedo, A. A., y Chaux, J. A. (2016). Aproximaciones a los videojuegos y su incidencia en las subjetividades de los jugadores latinoamericanos. Aposta. Revista de Ciencias Sociales, (69), 140-157. 
Acevedo-Merlano, A. A. (2018). Rastreando las claves de la subjetividad en los videojuegos. En I. Llerena-Rangel y J. González-Cueto (Comps.), Community: Prácticas socioculturales $y$ narrativas transmedia (pp. 81-112). Educosta, Corporación Universidad de la Costa.

Arbeláez-Campillo, D. F., Villasmil, J. J., y Rojas-Bahamón, M. J. (2021). Inteligencia artificial y condición humana: ¿Entidades contrapuestas o fuerzas complementarias? Revista de Ciencias Sociales (Ve), XXVII(2), 502-513. https://doi.org/10.31876/rcs. v27i2.35937

Belli, S., y López, C. (2008). Breve historia de los videojuegos. Athenea Digital, (14), 159-179.

Bringué, X., Sádaba, C., y Artopoulos, A. (2014). La generación interactiva en Argentina: niños y adolescentes ante las pantallas. Education Policy Analysis Archives, 22(49), 1-23. https://doi.org/10.14507/epaa. $\mathrm{v} 22 \mathrm{n} 49.2014$

Cabra, N. A. (2010). Videojuegos: Máquinas del tiempo y mutaciones de la subjetividad. Signo $y$ Pensamiento, XXIX(57), 162-177.

Cabra, N. A. (2013). Muñecas de plomo y soldaditos de trapo: el videojuego como migración a otras experiencias de género. Nómadas, (39), 165-179.

Cobo, R. (2006). Las multitudes inteligentes de la era digital. Revista Digital Universitaria, 7(6), 2-17.

Corona, A. (2016). El otro lúdico: El problema de la representación de la otredad en el videojuego. Razón y Palabra, 20(1_92), 1493-1508.

De Certeau, M. (2000). La invención de lo cotidiano I. Artes de hacer. UIA-Iteso.

Islas-Carmona, J. O. (2008). El prosumidor.
El acto comunicativo de la sociedad de la ubicuidad. Palabra Clave, 11(1), 29-39.

Latour, B. (2008). Reensamblar lo social: Una introducción a la teoría del actor-red. Editorial Manantial.

Loayza, J. (2010). Los videojuegos on-line en Latinoamérica: Impacto en las redes sociales y de consumo. Icono 14 , Revista de comunicación y tecnologías emergentes, 8(1), 59-74. http://dx.doi. org/10.7195/ri14.v8i1.280

Marín, V., Morales, M., y Reche, E. (2020). Aprendizaje con videojuegos con realidad aumentada en educación primaria. Revista de Ciencias Sociales (Ve), XXVI(E-2), 94-112. https://doi. org $/ 10.31876 /$ rcs.v26i0.34116

McLuhan, M. (2009). Comprender los medios de comunicación: Las extensiones del ser humano. Ediciones Paidós Ibérica.

Moncada, J., y Chacón, Y. (2012). El efecto de los videojuegos en variables sociales, psicológicas y fisiológicas en niños y adolescentes. RETOS. Nuevas Tendencias en Educación Física, Deporte y Recreación, 21, 43-49. https://doi.org/10.47197/retos. $\underline{\mathrm{v} 0 \mathrm{i} 21.34603}$

Navone, S. L. (2016). La máscara de Ulises: Videojuegos, narrativa $\mathrm{y}$ masculinidades. Nómadas, (44), 241254.

Torres-Parra, C. R. (2013). De la promesa digital a los videojuegos del oprimido. Claves sobre un uso de resistencia a través del consumo cultural. Palabra Clave, 16(3), 760-786.

Trivi, M. (11 de marzo de 2019). Cómo usa la violencia Rape Day, el videojuego sobre violaciones a mujeres. El País. https:// verne.elpais.com/verne/2019/03/08/ articulo/1552040360 194382.html

Venegas, A. (2019). Emergencia y 
formación de subjetividades históricas en los videojuegos de acción contemporáneos. El caso del desembarco de Normandía. Tropelias:
Revista de Teoría de la Literatura y Literatura Comparada, (31), 116-131. https://doi.org/10.26754/ojs tropelias/ tropelias.2019313091 